\title{
Role of functional groups in surface bonding of planar $\pi$-conjugated molecules
}

\author{
Oliver Bauer, ${ }^{1, *}$ Giuseppe Mercurio, ${ }^{2,3}$ Martin Willenbockel, ${ }^{2,3}$ Werner Reckien, ${ }^{1}$ Christoph Heinrich Schmitz, \\ Benjamin Fiedler, ${ }^{1}$ Serguei Soubatch, ${ }^{2,3}$ Thomas Bredow, ${ }^{1}$ Frank Stefan Tautz, ${ }^{2,3}$ and Moritz Sokolowski ${ }^{1}$ \\ ${ }^{1}$ Institut für Physikalische und Theoretische Chemie der Universität Bonn, Wegelerstrasse 12, 53115 Bonn, Germany \\ ${ }^{2}$ Peter Grünberg Institut (PGI-3), Forschungszentrum Jülich, 52425 Jülich, Germany \\ ${ }^{3}$ Jülich Aachen Research Alliance (JARA), Fundamentals of Future Information Technology, 52425 Jülich, Germany
} (Received 14 March 2012; revised manuscript received 21 August 2012; published 18 December 2012)

\begin{abstract}
The trends in the bonding mechanism of 3,4,9,10-perylenetetracarboxylic acid dianhydride (PTCDA) to the $\mathrm{Ag}(111), \mathrm{Ag}(100)$, and $\mathrm{Ag}(110)$ surfaces were analyzed on the basis of data obtained from x-ray standing waves and dispersion-corrected density functional theory. Of importance are the attractive local O-Ag bonds on the anhydride groups. They are the shorter, the more open the surface is, and lead even to partly repulsive interactions between the perylene core and the surface. In parallel, there is an increasing charge donation from the Ag surface into the $\pi$ system of the PTCDA. This synergism explains the out-of-plane distortion of the adsorbed PTCDA and the surface buckling.
\end{abstract}

DOI: 10.1103/PhysRevB.86.235431

PACS number(s): 68.43.Fg, 68.43.Bc, 73.20.Hb, 82.65.+r

\section{INTRODUCTION}

Presently, the surface bonding mechanism of large $\pi$ conjugated molecules is a subject of intense experimental and theoretical research, especially when the organic molecules carry functional groups. ${ }^{1-4}$ A key aspect concerns the role of the functional groups in relation to the extended $\pi$ system. While detailed bonding concepts are discussed for the chemisorption of small molecules, ${ }^{5-9}$ their application to the adsorption of large organic molecules is demanding. In general, the bonding cannot be explained by one particular type of interaction alone, e.g. van der Waals (vdW), electrostatic, or covalent interactions. We will refer to locally confined interactions of a specific physical/chemical type as bonding channels in the following. Most interesting is the situation when several competing bonding channels are involved. Although theoretical decomposition schemes exist, ${ }^{10}$ it is difficult then to clarify their particular role, since any variation of the molecular structure or the substrate leads to combined modifications. However, as we report here, insight can be obtained from a detailed determination of the bonding configuration of the same molecule on different crystal faces of one substrate, including the positions of all relevant atoms.

We have analyzed the adsorption geometry and the bonding mechanism of the planar organic molecule 3,4,9,10perylenetetracarboxylic acid dianhydride (PTCDA) on the low-index Ag surfaces (111), (100), and (110). PTCDA consists of an aromatic perylene core $\left(\mathrm{C}_{\text {peryl }}\right)$ and two functional anhydride groups containing $\mathrm{C}$ atoms $\left(\mathrm{C}_{\text {funct }}\right)$ and chemically inequivalent $\mathrm{O}$ atoms, namely carboxylic $\left(\mathrm{O}_{\text {carb }}\right)$ and anhydride $\mathrm{O}$ atoms [ $\mathrm{O}_{\text {anhyd }}$; see Fig. 4(b) below]. Thus, two bonding channels have been discussed controversially for chemisorbed PTCDA. The first via the heteroatoms in the functional groups ${ }^{1}$ and the second via the perylene core. ${ }^{11}$ PTCDA forms commensurate monolayer structures on all three Ag surfaces that are illustrated in Fig. 1 (top). On $\operatorname{Ag}(111)$, PTCDA forms a herringbone structure which is favored by quadrupole and intermolecular hydrogen bond-like interactions. ${ }^{12}$ On $\mathrm{Ag}(100)$, however, a T-shape arrangement, ${ }^{13}$ and on $\mathrm{Ag}(110)$, a brick-wall pattern is observed. ${ }^{12}$ Hence, the intermolecular arrangement of the herringbone structure is lost stepwise in this sequence, indicating an increasing importance of the molecule/substrate interactions.

The adsorption geometries have been derived from normal incidence x-ray standing waves (NIXSW) experiments, which allow the exact determination of the positions of chemically inequivalent atoms (within a molecule) on a surface. $^{14}$ It has already been demonstrated ${ }^{1,15}$ that the vertical adsorption heights of $\mathrm{O}_{\text {carb }}$ and $\mathrm{O}_{\text {anhyd }}$ are different for PTCDA/Ag(111) and that the molecule exhibits a saddle-like adsorption conformation [see Fig. 1(a)]. Here, we performed NIXSW with higher chemical resolution for PTCDA on $\operatorname{Ag}(100)$ and $\operatorname{Ag}(110)$, complementing the earlier results for PTCDA/Ag(111). Thus, the $\mathrm{C}_{\text {funct }}$ atoms could be analyzed independently from those in the perylene core $\left(\mathrm{C}_{\text {peryl }}\right)$, yielding the distortion of the $\mathrm{C}$ backbone of adsorbed PTCDA. In addition, we performed density functional theory (DFT) calculations of the periodic structures. These yielded information on the displacements of the Ag surface atoms upon adsorption, which are not accessible by NIXSW. Furthermore, electron densities from DFT demonstrate the charge redistributions and the bond formation. We employed the plane-wave code Vienna $A b$ initio Simulation Package (VASP) in combination with the projector-augmented wave (PAW) method. ${ }^{16,17} \mathrm{We}$ applied the Perdew-Burke-Ernzerhof (PBE) functional, ${ }^{18}$ which was revised with the $\mathrm{D} 3(\mathrm{BJ})$ correction $^{19}$ in order to describe the dispersion interactions. A comparison with earlier DFT calculations ${ }^{2,4,20}$ will be reported in two forthcoming publications. ${ }^{21,22}$

\section{EXPERIMENTAL AND THEORETICAL DETAILS}

\section{A. Experimental}

All normal incidence x-ray standing waves (NIXSW) experiments were performed at the undulator beam line ID32 of the European Synchrotron Radiation Facility (ESRF) at Grenoble, France. Two different experimental setups were used: In the case of PTCDA/Ag(110), the photoemission spectra were taken at an angle of $45^{\circ}$ with respect to the incoming beam with a PHI hemispherical electron analyzer of $150 \mathrm{~mm}$ radius and a 16-channel detector system. For 
(a) $\mathrm{Ag}(111)$

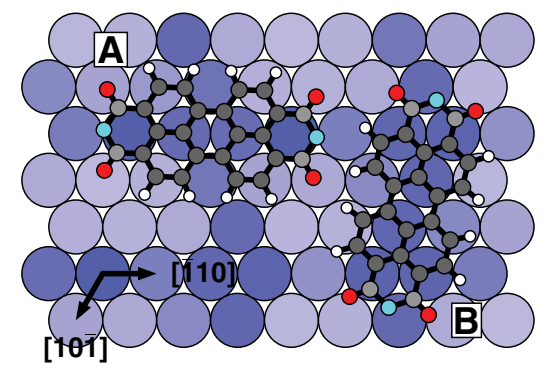

d (Å)

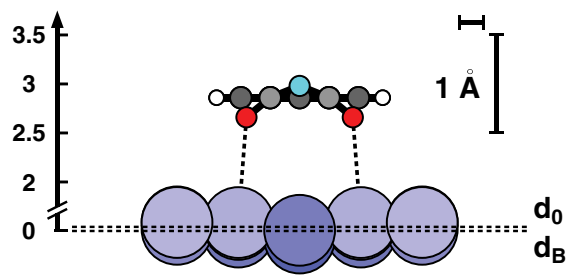

d (Å)

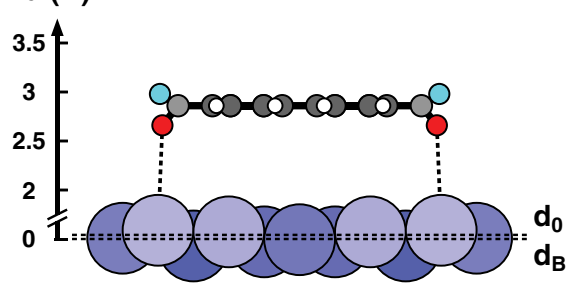

(b) $\mathrm{Ag}(\mathbf{1 0 0 )}$

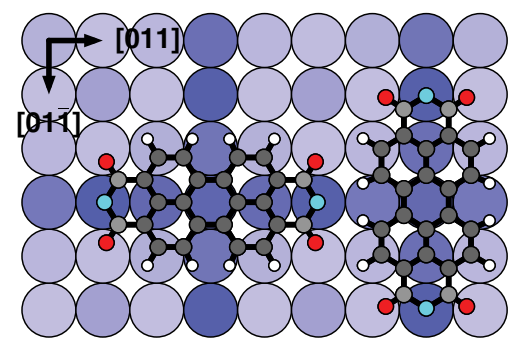

(c) $\mathrm{Ag}(110)$

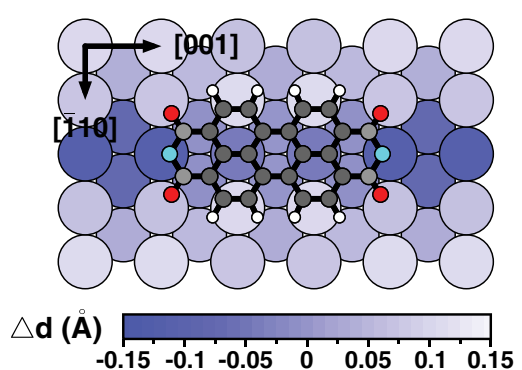

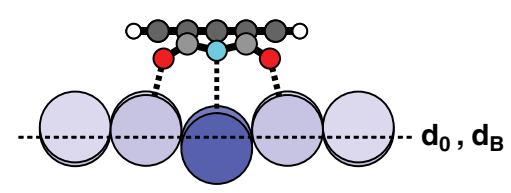
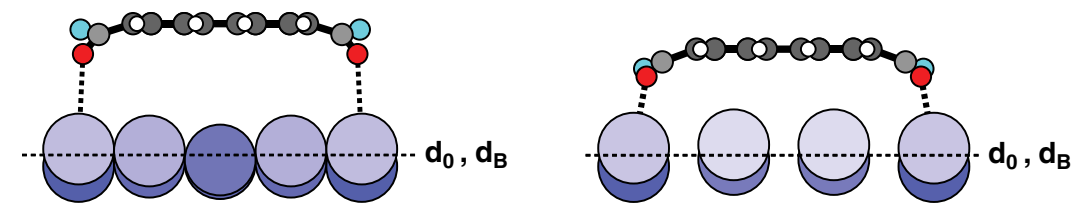

FIG. 1. (Color) Hard sphere models of the lateral and vertical molecular geometry of PTCDA on (a) $\operatorname{Ag}(111)$, (b) $\operatorname{Ag}(100)$, and (c) $\operatorname{Ag}(110):^{12,13,15,51,52}$ Top views (top), side views along the long (middle) and along the short molecular axis (bottom). Ag atoms are shown in different shades of blue to indicate the vertical deviation $\Delta d$ from their position in the relaxed uncovered surface (dashed line, $d_{0}$ ); $\mathrm{H}$ atoms are shown in white, $\mathrm{C}_{\text {funct }} / \mathrm{C}_{\text {peryl }}$ in light gray/gray, and $\mathrm{O}_{\text {carb }} / \mathrm{O}_{\text {anhyd }}$ in red/blue. In the side views, $d$ denotes the vertical adsorption height; the vertical scale is enlarged by a factor of 4 and referenced against the Bragg plane (dashed line, $d_{\mathrm{B}}$ ). The adsorption geometry of PTCDA is taken from the NIXSW experiments and the surface buckling from DFT calculations. O-Ag interactions are illustrated by black dotted lines. For (a) $\mathrm{Ag}(111)$, the side views refer to the molecule A ${ }^{58}$ For clarity, we show only the molecules within one unit cell of the periodic structure.

PTCDA/Ag(100), the photoemission spectra were conducted at an angle of $90^{\circ}$ employing a SPECS PHOIBOS 225 hemispherical electron analyzer. The photon energy was scanned successively in steps of $0.10-0.15 \mathrm{eV}$ in an interval of about 4-5 eV around the Bragg energy of the (220) and (200) reflections of the respective Ag substrates. Note that the (110) and (100) Bragg reflections are systematically extinct due to the fcc bulk structure of Ag. For PTCDA/Ag(100), also the (111) reflection was employed for the determination of the PTCDA adsorption site. The calculated Bragg energies, assuming a Bragg angle of $\theta_{\mathrm{Bragg}}=88^{\circ}$ and a Ag lattice constant of $4.085 \AA \AA^{23}$ are 4294.6, 3036.7, and $2629.9 \mathrm{eV}$ for the (220), (200), and (111) reflections. The photon flux is estimated at about 40 photons per molecule and second. ${ }^{15,24}$ For experimental details concerning the $\operatorname{Ag}(111)$ surface, we refer to Ref. 15.

The NIXSW data were collected by monitoring the intensities of various substrate and adsorbate signals by Auger electron (AES) and/or x-ray photoemission spectroscopy (XPS). In addition, photoemission spectra at photon energies of $10-15 \mathrm{eV}$ below the Bragg energies were taken with improved statistics in order to develop fit models of chemically different species of one element (see below). For PTCDA/Ag(110), a pass energy of $47 \mathrm{eV}$ was used to conduct the $\mathrm{Ag} M V V, \mathrm{Ag} 3 d$,
$\mathrm{C} 1 s$, and $\mathrm{O} 1 s$ Auger and photoemission spectra, respectively, while for PTCDA/ $\operatorname{Ag}(100)$, pass energies of $50 \mathrm{eV}(\mathrm{Ag} 3 d)$ or $100 \mathrm{eV}(\mathrm{Ag} M V V, \mathrm{C} 1 s$ and $\mathrm{O} 1 s)$ were employed. Typical recording times for an NIXSW experiment were 60 to $120 \mathrm{~min}$ for the adsorbate signals. To exclude beam damage, the shape of the adsorbate XPS signals was carefully observed as a function of beam exposure. Besides, as a precaution, a new position of the beam on the sample was chosen after every other NIXSW scan at the latest.

The intensity of the reflected $\mathrm{x}$-ray beam was monitored by the photoelectron current generated on a screen at a small angle close to the incoming $\mathrm{x}$-ray beam. Prior to the data collection, the position of the x-ray beam on the clean sample was optimized in order to give the narrowest reflectivity curve, which typically had a half width of $0.80 \mathrm{eV}$ for the (220), $0.75 \mathrm{eV}$ for the (200), and $0.95 \mathrm{eV}$ for the (111) reflection, respectively. The intensity of the primary x-ray beam was monitored by the photoelectron current generated on an $\mathrm{Al}$ foil in the beam path.

All experiments were carried out under ultrahigh vacuum (UHV) conditions at room temperature. The experiments were performed in two individual beam times in two different UHV systems. The measurements on PTCDA/Ag(110) were done in a single-chamber UHV system equipped with the 
TABLE I. Nondipolar parameters for the evaluation of the NIXSW photoelectron yield curves for the C1s and O1s XPS signals of PTCDA on $\operatorname{Ag}(100)$ [reflections (111) and (200)] and on $\operatorname{Ag}(110)$ [reflection (220)] and the $\operatorname{Ag} 3 d$ XPS signal of the substrates. The parameters $\beta, \delta, \gamma$, and $\Delta$ are derived from theoretical values of the free atoms, ${ }^{35,36}$ in the case of $\beta, \delta, \gamma$ via interpolation of the tabulated values, and can be converted into the parameters $Q, S_{R},\left|S_{I}\right|$, and $\psi$, respectively. ${ }^{32-34}$ In addition, the nominal Bragg energies $\mathrm{E}_{\mathrm{Bragg}}$ and the angles $\alpha$ between the primary x-ray beam and the photoelectron analyzer are given. For the determination of $Q, S_{R},\left|S_{I}\right|$, and $\psi$, the angle $\theta$, i.e. the angle of the electron emission/detection direction relative to the photon polarization vector, has to be considered, and it is calculated as $\theta=90^{\circ}-\alpha$ (the primary x-ray beam is linearly polarized). Note that for the measurements on PTCDA/Ag(100) the nondipolar parameters $Q$ and $\psi$ equal zero due to the specific experimental geometry $\left(\theta=0^{\circ}\right)$. For the photoemission from an initial $s$ state, $\beta$ and $\delta$ are approximated as two and zero, respectively. ${ }^{32,33}$ For the emission from an initial $d$ state, $\beta$ and $\delta$ are taken from Ref. 36, and $S_{R}$ and $\left|S_{I}\right|$ are calculated according to Ref. 33, while $\Delta$ values are not available and thus are set to zero.

\begin{tabular}{|c|c|c|c|c|c|c|c|c|c|}
\hline \multirow{4}{*}{$\begin{array}{l}\text { Reflection (hkl) } \\
\mathrm{E}_{\mathrm{Bragg}}(\mathrm{eV}) \\
\alpha\left(^{\circ}\right) \\
\text { XPS signal }\end{array}$} & \multicolumn{3}{|c|}{ (111) } & \multicolumn{3}{|c|}{ (200) } & \multicolumn{3}{|c|}{$(220)$} \\
\hline & \multicolumn{3}{|c|}{2629.9} & \multicolumn{3}{|c|}{3036.7} & \multicolumn{3}{|c|}{4294.6} \\
\hline & \multicolumn{3}{|c|}{90} & \multicolumn{3}{|c|}{90} & \multicolumn{3}{|c|}{45} \\
\hline & $\mathrm{C} 1 s$ & $\mathrm{O} 1 s$ & $\operatorname{Ag} 3 d$ & $\mathrm{C} 1 s$ & $\mathrm{O} 1 s$ & $\operatorname{Ag} 3 d$ & $\mathrm{C} 1 s$ & $\mathrm{O} 1 s$ & $\operatorname{Ag} 3 d$ \\
\hline$\beta$ & 2.00 & 2.00 & 1.12 & 2.00 & 2.00 & 1.07 & 2.00 & 2.00 & 0.94 \\
\hline$\delta$ & 0.00 & 0.00 & 0.09 & 0.00 & 0.00 & 0.11 & 0.00 & 0.00 & 0.15 \\
\hline$\gamma$ & 1.06 & 0.98 & 0.63 & 1.16 & 1.09 & 0.72 & 1.42 & 1.35 & 0.95 \\
\hline$\Delta$ & -0.21 & -0.30 & 0.00 & -0.20 & -0.27 & 0.00 & -0.17 & -0.23 & 0.00 \\
\hline$Q$ & 0.00 & 0.00 & 0.00 & 0.00 & 0.00 & 0.00 & 0.34 & 0.32 & 0.36 \\
\hline$\widehat{S}_{R}$ & 1.00 & 1.00 & 1.00 & 1.00 & 1.00 & 1.00 & 2.01 & 1.93 & 2.12 \\
\hline$\left|S_{I}\right|$ & 1.00 & 1.00 & 1.00 & 1.00 & 1.00 & 1.00 & 1.51 & 1.47 & 1.56 \\
\hline$\psi$ & 0.00 & 0.00 & 0.00 & 0.00 & 0.00 & 0.00 & -0.06 & -0.07 & 0.00 \\
\hline
\end{tabular}

typical surface preparation methods and Omicron back-view low-energy electron diffraction (LEED) optics. For the measurements on PTCDA/Ag(100), a UHV system with a preparation chamber and a separate experimental chamber was used. The former offered typical surface preparation methods, SPECS back-view LEED optics, and a Pfeiffer Vacuum PrismaPlus mass spectrometer.

The $\operatorname{Ag}(110)$ and $\operatorname{Ag}(100)$ samples were prepared by repeated cycles of sputtering and annealing. X-ray photoemission spectroscopy and LEED were employed to check the cleanliness and the structural order of the prepared surfaces. For PTCDA/Ag(110), the base pressure of the UHV system was $7 \times 10^{-10}$ mbar. The crystal was sputtered for 30-60 min with $\mathrm{Ar}^{+}$ions of $1.5 \mathrm{keV}$ kinetic energy, using an ion current of $20 \mu \mathrm{A} / \mathrm{cm}^{2}$ on the sample. Subsequently, the sample was annealed at $850 \mathrm{~K}$ for 30-60 min. PTCDA was evaporated from a homemade Knudsen cell with a deposition rate of 1.0 ML/min. After the deposition, the sample was annealed at $420 \mathrm{~K}$ for $10 \mathrm{~min}$ to improve the order within the adsorbate layer. The coverage of the PTCDA was deduced from the XPS intensity of the $\mathrm{C} 1 s$ signal in comparison to that of $1 \mathrm{ML}$ of PTCDA on $\mathrm{Ag}(111),{ }^{15}$ yielding a coverage of $0.9 \pm 0.1 \mathrm{ML}$ (Ref. 22).

In the case of PTCDA/Ag(100), the preparation parameters were as follows: Base pressures of $8 \times 10^{-10}$ mbar and $4 \times$ $10^{-10}$ mbar for the preparation chamber and the experimental chamber, respectively, sputtering with $\mathrm{Ar}^{+}$ions of $850 \mathrm{eV}$ kinetic energy and an ion current of $10 \mu \mathrm{A} / \mathrm{cm}^{2}$ on the sample for 15-30 min, subsequent annealing at $1000 \mathrm{~K}$ between 30 and 90 min. PTCDA was deposited from a homemade Knudsen cell, which was carefully calibrated prior to the preparation using thermal programmed desorption (TPD) spectroscopy by monitoring a fragment of the PTCDA molecule (124 amu). The absolute PTCDA coverage was verified by means of
XPS, yielding a coverage of $0.8 \pm 0.1$ and $0.25 \pm 0.06 \mathrm{ML}$, respectively, for the two preparations reported here. The deposition rates were $1.0 \mathrm{ML} / \mathrm{min}$ and below. The long-range order of the PTCDA layers was proven by the bright and sharp LEED patterns for $\operatorname{Ag}(110)$ (Ref. 22) and $\operatorname{Ag}(100)$.

\section{B. Experimental data treatment}

The XPS data were analyzed employing the program CasaXPS. $^{25}$ The energy scales of the XP spectra were calibrated using the position of the $\mathrm{Ag} 3 d$ signal $^{26,27}$ as a reference. A background of linear or Shirley ${ }^{28}$ type was subtracted from the individual XP spectra. The substrate Auger and XP spectra were numerically integrated, while for the adsorbate signals, sophisticated fit models were employed (see below). The errors of the integral intensities were computed by means of the Monte Carlo procedure embedded in CasaXPS. ${ }^{22,25,29}$ These statistical errors were propagated to the NIXSW curves. In addition, our fit models were validated by the fact that these gave the highest coherent fractions $f_{\mathrm{c}}$ in comparison with alternative models.

All experimental NIXSW data were normalized to the intensity of the primary $\mathrm{X}$-ray beam. The obtained NIXSW photoelectron yield curves were fitted with the data evaluation routine XSWAVES. ${ }^{30}$ Identical results (within the errors) were obtained with the independent XSW program Torricelli, ${ }^{29,31}$ ensuring the absence of systematic and/or numerical errors by the evaluation routines. Due to the high photon energies employed in these experiments, nondipolar correction terms had to be considered in the fitting process. ${ }^{32-34}$ These parameters were calculated from tabulated values for $\beta, \delta, \gamma$, and $\Delta^{35,36}$ for the relevant photon energies, XPS levels and experimental geometries in this study. They are listed in Table I. Often, the nondipolar corrections are expressed in terms of the 
parameters $Q, S_{R},\left|S_{I}\right|$, and $\psi$, which are also given in Table I. For the AgMVV Auger signal, possible photoelectronstimulated contributions ${ }^{34,37}$ were neglected. As nondipolar effects generally do not apply to Auger signals, ${ }^{34} \gamma$ and $\Delta$ were set to zero.

\section{Theoretical methods}

For the DFT studies on the periodic systems, the plane-wave code VASP ${ }^{17,38,39}$ in combination with the projector-augmented wave method, ${ }^{16}$ in order to account for the core electrons, was used. A cutoff energy of $400 \mathrm{eV}$ for the plane-wave valence basis and a Monkhorst-Pack integration setup with a $3 \times 3 \times$ $1 k$-point mesh was chosen. These values had been obtained in preliminary convergence studies as an optimal compromise between accuracy and computational efficiency. The PBE functional $^{18}$ was applied in combination with an empirical dispersion correction. ${ }^{19,40,41}$ This approach has already been successfully tested for periodic systems whose interactions are dominated by dispersion forces. ${ }^{42,43}$ The dispersion corrected DFT-D energy $E_{\mathrm{DFT}}$ is calculated by adding an empirical correction energy $E_{\text {disp }}$ to the Kohn-Sham energy $E_{\mathrm{KS}-\mathrm{DFT}}$, see Eq. (1):

$$
E_{\mathrm{DFT}}=E_{\mathrm{KS}-\mathrm{DFT}}+E_{\mathrm{disp}} .
$$

Calculations with the original $\mathrm{D} 3^{41}$ as well as with the new D3(BJ) dispersion correction ${ }^{19}$ were performed. However, only the PBE-D3(BJ) results are presented here since these show a slightly better agreement with the experimental data. The silver surfaces were modeled by a $\left(\begin{array}{ll}3 & -2 \\ 6 & 7\end{array}\right)$ super cell for the $\operatorname{Ag}(111)$ surface, a $\left(\begin{array}{cc}4 & 4 \\ -4 & 4\end{array}\right)$ super cell for the $\operatorname{Ag}(100)$ surface and a $\left(\begin{array}{cc}3 & 2 \\ -3 & 2\end{array}\right)$ super cell for the $\mathrm{Ag}(110)$ surface, respectively. The slabs consisted of three $\mathrm{Ag}$ layers for $\mathrm{Ag}(111)$ and $\mathrm{Ag}(100)$ and seven layers for $\mathrm{Ag}(110)$. The $\mathrm{Ag}$ atoms in the bottom layers [one for the (111) as well as the (100) surface and two for the (110) surface, respectively] were fixed to their ideal bulk position during the structural optimization process. PTCDA monolayers were obtained by the adsorption of two molecules for $\mathrm{Ag}(111)$ and $\mathrm{Ag}(100)$ and one molecule for $\mathrm{Ag}(110)$, respectively, see Fig. 1. The net charge transfer from the Ag surfaces to the adsorbed PTCDA molecule was studied on the basis of a Bader analysis ${ }^{44,45}$ of the electron density $\rho(\mathbf{r})$. The electron densities $\rho(\mathbf{r})$ and the electron density differences $\Delta \rho(\mathbf{r})$ (see Fig. 5 below) which were obtained from the DFT calculations in VASP were analyzed with the program XCrySDen. ${ }^{46}$ Here, $\Delta \rho(\mathbf{r})$ is defined as $\rho(\mathbf{r})$ of the bonded system PTCDA/Ag(hkl) minus $\rho(\mathbf{r})$ of the free (but distorted) PTCDA molecule and minus $\rho(\mathbf{r})$ of the bare (but buckled) Ag(hkl) surface, see Eq. (2):

$$
\begin{aligned}
\Delta \rho(\mathbf{r})= & \rho_{\mathrm{PTCDA}} / \operatorname{Ag}(\mathrm{hkl}) \\
& -\rho_{\mathrm{Ag}(\mathrm{hkl}), \text { buckled }}(\mathbf{r}) .
\end{aligned}
$$

\section{EXPERIMENTAL RESULTS}

The $\mathrm{C} 1 s$ and $\mathrm{O} 1 s$ XP spectra of PTCDA on $\mathrm{Ag}(100)$ and on $\operatorname{Ag}(110)$ were fitted with several components. This allowed to differentially analyze the chemically inequivalent species of one element within the molecule. Exemplary XP spectra, which were taken at photon energies of $10-15 \mathrm{eV}$ below the respective Bragg energies, are shown in Fig. 2. For the main lines, a linear combination of a Gaussian and a Lorentzian profile was used. Lorentzian contributions of 10 $20 \%$ gave the best agreement with the experimental data. The corresponding satellite peaks were fitted with pure Gaussians. All fit models meet the expected stoichiometry of the PTCDA molecule, i.e. $\mathrm{C}_{\text {peryl }}: \mathrm{C}_{\text {funct }}=20: 4$ and $\mathrm{O}_{\text {carb }}: \mathrm{O}_{\text {anhyd }}=4: 2$. The detailed parameters of the fit models will be given in two forthcoming publications [Ref. 21 for $\mathrm{Ag}(100)$ and Ref. 22 for $\operatorname{Ag}(110)]$.

The so-obtained XPS fit models were employed in the NIXSW data analysis. The relative intensities $C_{\text {peryl }}: C_{\text {funct }}$ and $\mathrm{O}_{\text {carb }}$ : $\mathrm{O}_{\text {anhyd }}$ were allowed to vary throughout the NIXSW scan, while the full width at half-maximum (FWHM) and the relative position of the peaks were constrained. Exemplary NIXSW photoelectron yield curves for the measurements on the (200) and (220) reflections are shown in Fig. 3. A detailed discussion of the data is found in Sec. IV and in Refs. 21 and 22. The averaged results are summarized in Table II. For averaging, we used two $\operatorname{Ag} M V V$, four $\operatorname{Ag} 3 d$, seven $\mathrm{C} 1 s$, and seven O1s NIXSW datasets for PTCDA/Ag(100) and two $\mathrm{Ag} M V V$, one $\mathrm{Ag} 3 d$, two $\mathrm{C} 1 s$, and three $\mathrm{O} 1 s$ datasets for PTCDA/Ag(110) respectively. In the former case, NIXSW datasets with respect to the (111) Bragg reflection of the Ag bulk were also conducted, namely one for the $\mathrm{Ag} 3 d$ and four for the $\mathrm{O} 1 s$ signal. The errors in the coherent fractions $f_{\mathrm{c}}$ and in the coherent positions $p_{\mathrm{c}}$ that are given in Table II are derived as the standard deviation of the individual fit results, while the error in the vertical adsorption height $d^{\exp }$ is propagated from the error in $p_{\mathrm{c}}$.

For PTCDA/Ag(100), the adsorption site was determined by triangulation via NIXSW. ${ }^{34}$ An averaged coherent position $p_{\mathrm{c}}$ of $0.67 \pm 0.01$ was obtained for the $\mathrm{O}$ atoms with respect to the (111) lattice planes of the $\mathrm{Ag}$ bulk, which enclose an angle of $54.7^{\circ}$ with the surface. Our result can be assigned unambiguously to an on-top adsorption of the center of the PTCDA molecule (expected: 0.65; to be compared to 0.15 for the four-fold hollow site and an incoherent position for the bridge site).

In the case of PTCDA/Ag(110), we systematically find coherent fractions $f_{\mathrm{c}}$ which are the smallest within our datasets of PTCDA on $\mathrm{Ag}(111),{ }^{15} \mathrm{Ag}(100)$, and $\mathrm{Ag}(110)$ (see Table II), and also smaller than those usually obtained for organic adsorbates, see e.g. Refs. 47 and 48 . In particular, the $f_{\mathrm{c}}$ values of the $\mathrm{C}$ and $\mathrm{O}$ atoms in PTCDA on $\mathrm{Ag}(110)$ are reduced by about $20 \%$ and $50 \%$ with respect to those on $\mathrm{Ag}(100)$. From the quality of the LEED patterns, ${ }^{22}$ we can exclude that this is due to lateral disorder effects. It is much more likely that the effect is related to the significantly smaller lattice plane spacing in the case of the employed (220) reflection [by about $30 \%$ and $40 \%$, respectively, in comparison to the (200) and (111) reflections]. This causes $f_{\mathrm{c}}$ as well as $p_{\mathrm{c}}$ to be more sensitive to vertical displacements of the atoms with respect to the extended lattice planes. ${ }^{22,34,49}$ Hence, thermal vibrations lead to a stronger reduction of the $f_{\mathrm{c}}$ values. In addition, a small fraction of molecules at defect sites (which are more likely on this most open surface), which are in a structurally different adsorption geometry and lead to an incoherent contribution in the NIXSW curves, could play a role here. However, the $p_{\mathrm{c}}$ values will not be affected by this. 
0.8 ML PTCDA/Ag(100)

(a)

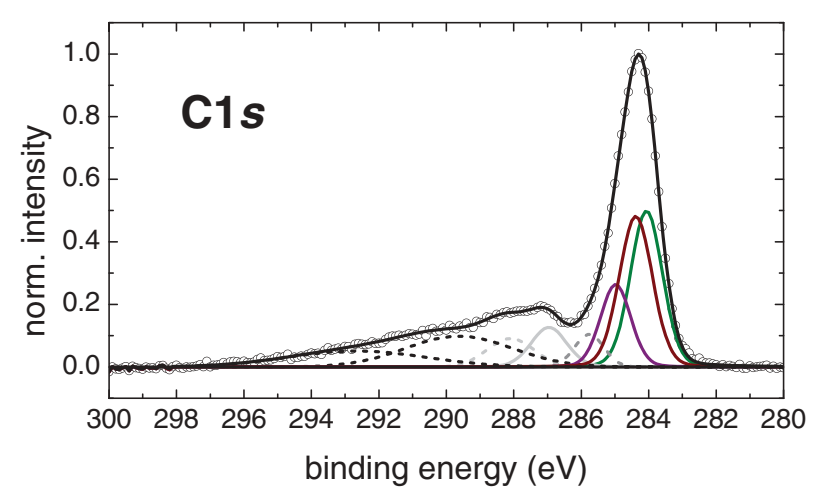

(c)

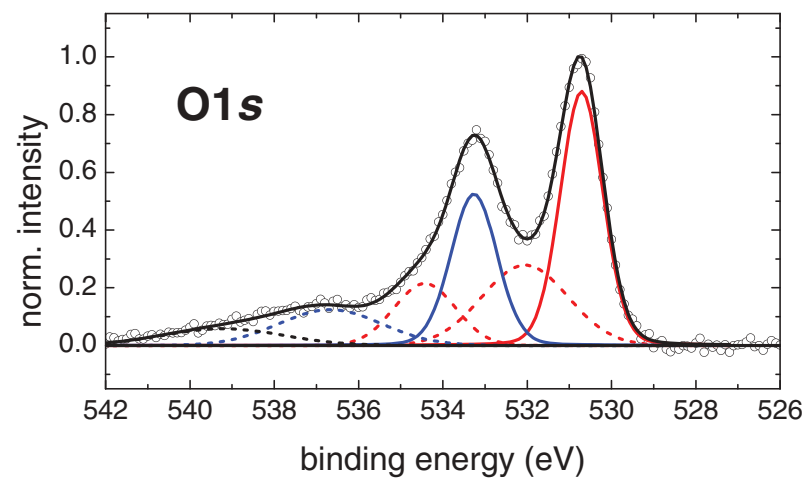

0.9 ML PTCDA/Ag(110)

(b)

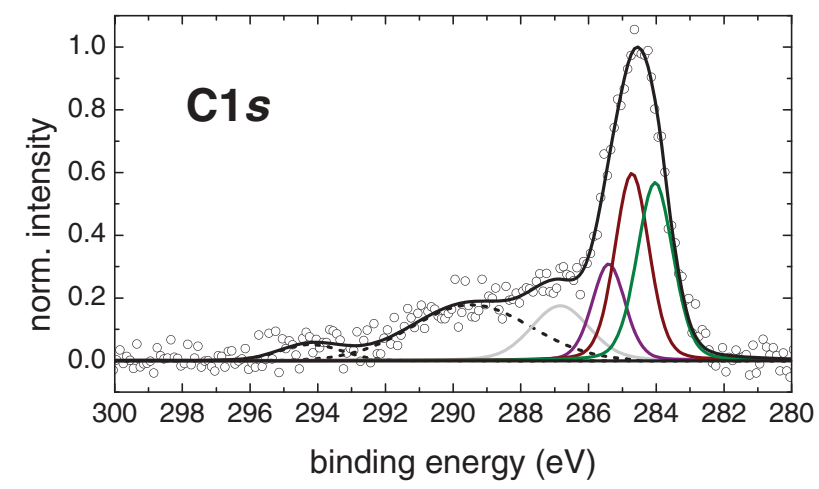

(d)

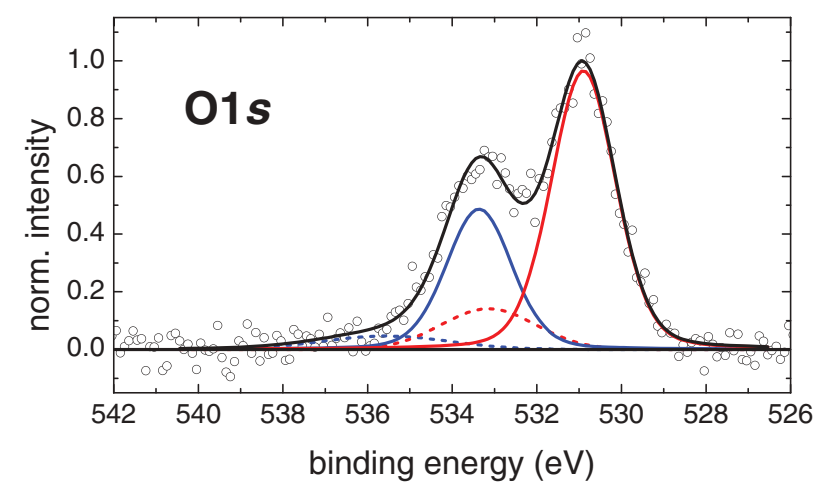

FIG. 2. (Color) Normalized x-ray photoemission spectra $(\bigcirc)$ for (a,c) PTCDA/Ag(100) and (b,d) PTCDA/Ag(110). The former were taken at an emission angle of $2^{\circ}$ and a photon energy of $3.024 \mathrm{keV}$, the latter at $45^{\circ}$ emission and $4.280 \mathrm{keV}$. All spectra are corrected with a linear or Shirley background function. (a) and (b) XP spectra of the $\mathrm{C} 1 s$ level. Green: $\mathrm{C}_{\mathrm{C}-\mathrm{C}}$, brown: $\mathrm{C}_{\mathrm{C}-\mathrm{H}}$, purple: $\mathrm{C}_{\mathrm{C}-\mathrm{CO}}$, gray: combined satellite corresponding to $\mathrm{C}_{\mathrm{C}-\mathrm{C}}, \mathrm{C}_{\mathrm{C}-\mathrm{H}}$, and $\mathrm{C}_{\mathrm{C}-\mathrm{CO}}$, light gray: $\mathrm{C}_{\text {funct }}$, black: unassigned satellites. Note that for the evaluation of the NIXSW data all $\mathrm{C}$ atoms of the perylene core are combined to give the $\mathrm{C}_{\text {peryl }}$ signal. (c) and (d) XP spectra of the O1s level. Red: $\mathrm{O}_{\text {carb }}$, blue: $\mathrm{O}_{\text {anhyd }}$, black: unassigned satellite. The main photoemission peaks are drawn as full lines, the (corresponding) satellite peaks as dashed lines, in respective colors. In addition, the resulting sum of all components is shown as a black line.

\section{THEORETICAL RESULTS AND DISCUSSION}

We now turn to the discussion of the experimental and theoretical results. This section is split into two parts. First, the observed adsorption geometries will be discussed in detail. Afterwards, we will review the electronic structure of the adsorbed PTCDA molecules.

\section{A. Adsorption geometry}

The NIXSW results for all three surfaces are summarized in Table III and illustrated in Fig. 1. Several trends can be seen: (1) In the sequence $\operatorname{Ag}(111), \operatorname{Ag}(100), \operatorname{Ag}(110)$, i.e. in the direction of decreasing surface atom density, the overall vertical adsorption height $d$ of PTCDA, taken to be equal to $d(\mathrm{C}$ total $)$, decreases by $0.30 \pm 0.01 \AA$. On all three $\mathrm{Ag}$ faces, the adsorption height is lower than expected for a pure vdW bonding. ${ }^{24}$ (2) The adsorption geometry changes from saddle-like to arch-like for the two more open surfaces, where all $\mathrm{O}$ atoms are located closer to the surface than the perylene core. (3) The $\mathrm{C}$ backbone distortion, i.e. $d\left(\mathrm{C}_{\text {peryl }}\right)-d\left(\mathrm{C}_{\text {funct }}\right)$, increases to $0.13 \pm 0.11 \AA$ for $\operatorname{Ag}(110),{ }^{50}$ and (4) the difference $d\left(\mathrm{O}_{\text {anhyd }}\right)-d\left(\mathrm{O}_{\text {carb }}\right)$ decreases by $75 \%$ in the above-stated sequence, i.e. it is reduced to $0.08 \pm 0.05 \AA$ [Fig. 4(a), solid lines]. The finding (1) proves a chemisorptive interaction of the molecule with the substrate that is strongest for the most open (110) face, where the lowest adsorption height is found. Hence, the findings (2)-(4) indicate the presence of significant chemical interactions, in particular between the $\mathrm{O}_{\text {carb }}$ and, to a smaller extent, the $\mathrm{O}_{\text {anhyd }}$ atoms and the Ag surface atoms. We will unveil this bonding channel on the anhydride groups further by looking at the bond lengths $b$ between the involved atoms.

For this purpose, the adsorption sites of PTCDA on the Ag surfaces have to be considered: For PTCDA/Ag(100), we determined the adsorption site with $\mathrm{NIXSW}^{21}$ (see also $\mathrm{Sec}$. III). We find that the $\mathrm{O}$ atoms reside above a $\mathrm{Ag}$ atom, while the $\mathrm{C}_{\text {funct }}$ atoms sit close to bridge sites [see Fig. 1(b)]. On $\mathrm{Ag}(110)$, the molecule adsorbs with its center on a bridge position above a groove ${ }^{51}$ as a consequence, the $\mathrm{O}$ atoms sit close to on-top positions, while the $\mathrm{C}_{\text {funct }}$ atoms occupy off-short-bridge positions i.e. positions close to short-bridge positions, [Fig. 1(c)]. On $\operatorname{Ag}(111)$, both molecules of the unit cell adsorb in bridge positions, but at different angles with respect to the close-packed $\langle\overline{1} 10\rangle$ substrate directions. ${ }^{52}$ One 
0.8 ML PTCDA/Ag(100)

(a)

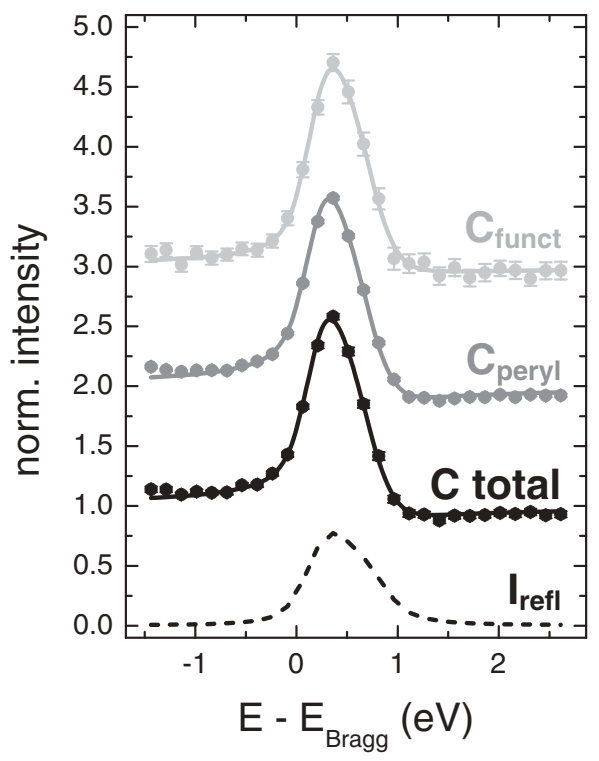

(c)

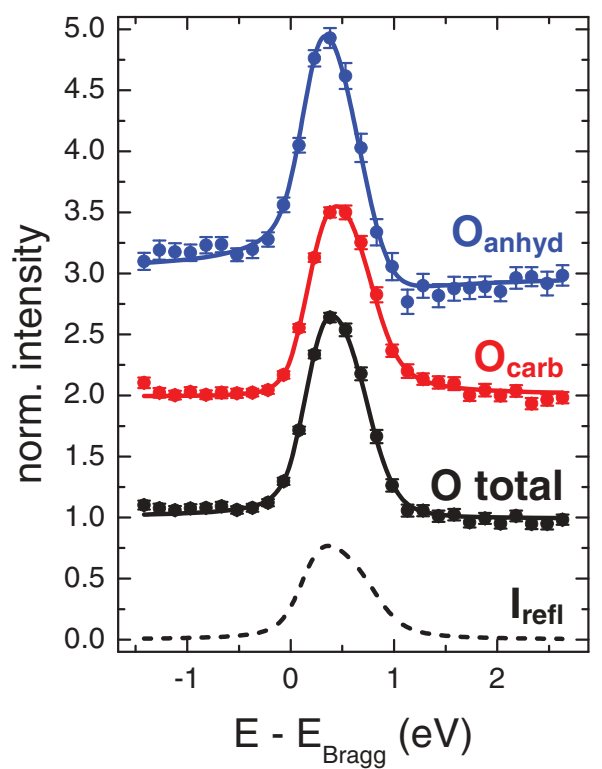

0.9 ML PTCDA/Ag(110)

(b)

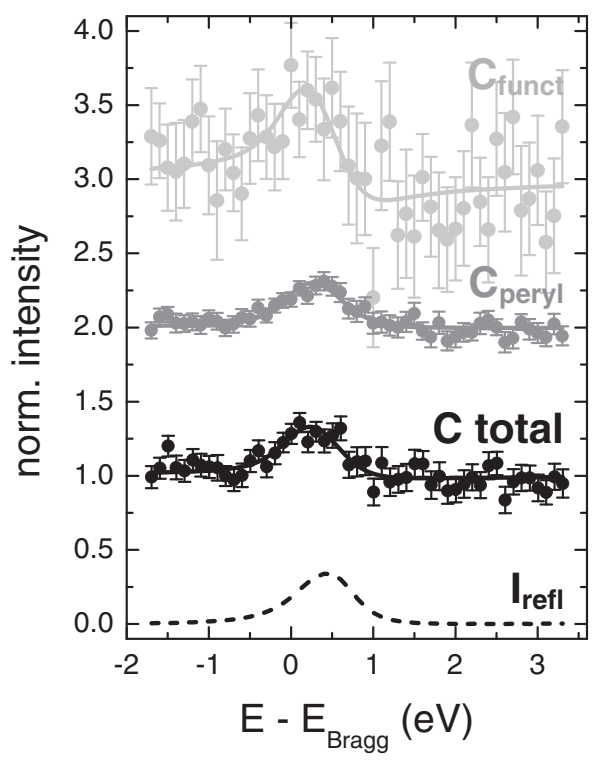

(d)

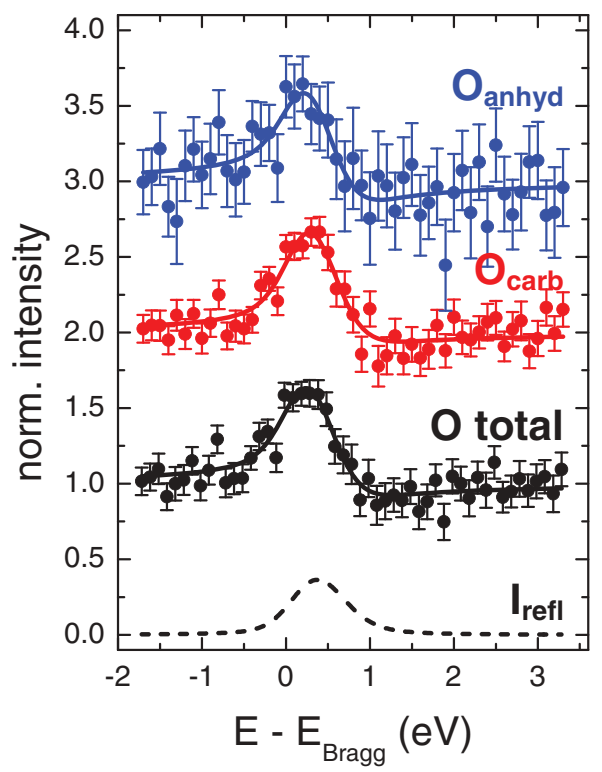

FIG. 3. (Color) Exemplary normal incidence x-ray standing waves photoemission yield curves for (a,c) PTCDA/Ag(100) and (b,d) PTCDA/Ag(110). The energy scales refer to the nominal Bragg energies (see Table I). Experimental data points are shown as circles, while fit results are given as full lines. The sophisticated XP fit models allow a differential analysis of the NIXSW data: (a) and (b) $\mathrm{C}_{\text {peryl }}$ (gray), $\mathrm{C}_{\text {funct }}$ (light gray), (c) and (d) $\mathrm{O}_{\text {carb }}$ (red), $\mathrm{O}_{\text {anhyd }}$ (blue). In addition, the summed data of the individual components are shown in black. The measured reflectivity curves (Darwin-Prins curves, $\mathrm{I}_{\text {refl }}$ ) are shown as dashed lines. Note that the scaling of the $x$ and $y$ axes is not identical for (a,c) PTCDA/Ag(100) and (b,d) PTCDA/Ag(110). Also, curves have been vertically offset for clarity. The lower signal-to-noise of the data for the $\mathrm{Ag}(110)$ surface is due to the smaller photoemission cross sections at the higher Bragg energy, a smaller transmission of the analyzer (see above), and a different data acquisition geometry.

molecule (A) is (nearly) aligned with the substrate, with the $\mathrm{O}_{\text {carb }}$ atoms being on-top and the $\mathrm{O}_{\text {anhyd }}$ as well as the $\mathrm{C}_{\text {funct }}$ atoms being in bridge sites. The second molecule $(\mathrm{B})$ is rotated versus $\langle\overline{1} 10\rangle$ and has all atoms within its functional groups roughly in bridge positions [Fig. 1(a)]. Since A and B are experimentally not distinguishable, average values for $d$ and $b$, respectively, are considered in the following.

The DFT results for the adsorption heights $d$ are summarized in Table III. They match the experimental values within $5 \%$ for all distinguishable atoms/groups. This renders 
TABLE II. Experimental NIXSW results (including statistical and systematic errors related to different evaluation routines) for the adsorption geometry of PTCDA on the $\operatorname{Ag}(100)$ and $\operatorname{Ag}(110)$ surfaces. Here, $f_{\mathrm{c}}$ and $p_{\mathrm{c}}$ are the coherent fractions and positions, respectively, which were obtained from the fits to the photoelectron yield curves. The $d^{\exp }$ values denote the averaged vertical adsorption height of the specific atoms (all values in $\AA$, n.d. $=$ not determined). Here, $d^{\exp }$ is calculated at $d^{\exp }=\left(n+p_{\mathrm{c}}\right) d_{\mathrm{H}}$ with $n=1$ for the adsorbate signals and $n=0$ for the substrate signals. $d_{\mathrm{H}}$ is the lattice plane spacing of the employed Bragg reflection of the Ag bulk. For the specification of the atoms, see Fig. 4(b). In the case of $\mathrm{C}$ and $\mathrm{O}$, the $\mathrm{C} 1 s$ and $\mathrm{O} 1 s$ levels were measured, respectively. The values for $\mathrm{C}$ total and $\mathrm{O}$ total were obtained by performing the fit of the NIXSW photoelectron yield curves to the sum of the integral intensities of all components contributing to the respective XPS signal. For $\operatorname{Ag}(111)$ data see Ref. 15.

\begin{tabular}{|c|c|c|c|c|c|c|c|c|c|}
\hline & \multicolumn{3}{|c|}{$\operatorname{Ag}(100)-(200)$ reflection } & \multicolumn{3}{|c|}{$\operatorname{Ag}(100)-(111)$ reflection } & \multicolumn{3}{|c|}{$\operatorname{Ag}(110)-(220)$ reflection } \\
\hline & $f_{\mathrm{c}}$ & $p_{\mathrm{c}}$ & $d^{\exp }$ & $f_{\mathrm{c}}$ & $p_{\mathrm{c}}$ & $d^{\exp }$ & $f_{\mathrm{c}}$ & $p_{\mathrm{c}}$ & $d^{\exp }$ \\
\hline $\mathrm{C}$ total & $0.50 \pm 0.08$ & $0.38 \pm 0.01$ & $2.81 \pm 0.02$ & n.d. & n.d. & n.d. & $0.38 \pm 0.05$ & $0.77 \pm 0.01$ & $2.56 \pm 0.01$ \\
\hline $\mathrm{C}_{\text {peryl }}$ & $0.50 \pm 0.10$ & $0.39 \pm 0.01$ & $2.84 \pm 0.02$ & n.d. & n.d. & n.d. & $0.38 \pm 0.07$ & $0.79 \pm 0.01$ & $2.58 \pm 0.01$ \\
\hline $\mathrm{C}_{\text {funct }}$ & $0.58 \pm 0.05$ & $0.34 \pm 0.01$ & $2.73 \pm 0.01$ & n.d. & n.d. & n.d. & $0.43 \pm 0.01$ & $0.69 \pm 0.08$ & $2.45 \pm 0.11$ \\
\hline O total & $0.55 \pm 0.06$ & $0.29 \pm 0.01$ & $2.64 \pm 0.02$ & $0.42 \pm 0.02$ & $0.67 \pm 0.01$ & n.d. & $0.26 \pm 0.03$ & $0.61 \pm 0.02$ & $2.33 \pm 0.03$ \\
\hline $\mathrm{O}_{\text {carb }}$ & $0.49 \pm 0.06$ & $0.24 \pm 0.01$ & $2.53 \pm 0.02$ & $0.35 \pm 0.01$ & $0.68 \pm 0.01$ & n.d. & $0.23 \pm 0.02$ & $0.59 \pm 0.03$ & $2.30 \pm 0.04$ \\
\hline $\mathrm{O}_{\text {anhyd }}$ & $0.77 \pm 0.03$ & $0.36 \pm 0.01$ & $2.78 \pm 0.02$ & $0.57 \pm 0.03$ & $0.66 \pm 0.01$ & n.d. & $0.33 \pm 0.06$ & $0.65 \pm 0.02$ & $2.38 \pm 0.03$ \\
\hline $\operatorname{Ag} 3 d$ & $0.90 \pm 0.01$ & $-0.01 \pm 0.01$ & $-0.01 \pm 0.01$ & $0.85 \pm 0.01$ & $-0.03 \pm 0.01$ & n.d. & $0.80 \pm 0.01$ & $-0.04 \pm 0.01$ & $-0.06 \pm 0.01$ \\
\hline $\operatorname{Ag} M V V$ & $0.86 \pm 0.01$ & $0.00 \pm 0.01$ & $0.00 \pm 0.02$ & n.d. & n.d. & n.d. & $0.87 \pm 0.05$ & $-0.01 \pm 0.01$ & $-0.02 \pm 0.01$ \\
\hline
\end{tabular}

the conclusions drawn from the DFT calculations meaningful. Moreover, we calculated the adsorption energies $E_{\text {ads }}$. By comparing the pure PBE and the dispersion-corrected PBE$\mathrm{D} 3(\mathrm{BJ})$ results, the vdW contribution to $E_{\text {ads }}$ is determined to be larger than $70 \%$ on all surfaces, e.g. approximately $3 \mathrm{eV}$ on $\mathrm{Ag}(110)$, leaving for the chemical interactions only an amount of maximal $1.4 \mathrm{eV}$. Nevertheless, the chemical interactions are decisive for the distortion and the site selectivity of the molecule upon adsorption. The adsorption energies nicely follow the trends of $d$ and $b$ in relation to the substrate faces [see Fig. 4(a)]. This is particularly true for $b\left(\mathrm{O}_{\text {carb/anhyd }}\right)$, indicating again the importance of the interactions between the $\mathrm{O}$ and the Ag surface atoms.

Important information from the DFT calculations is the finding that the $\mathrm{Ag}$ atoms below the center of the perylene core (and below the $\mathrm{O}_{\text {anhyd }}$ atoms) are repelled and pushed into the surface, while the $\mathrm{Ag}$ atoms below the $\mathrm{O}_{\text {carb }}$ atoms are pulled out (Fig. 1). Apparently, the interaction between the Ag atoms and the $\mathrm{C}$ backbone turns locally Pauli-repulsive when the PTCDA molecule is pulled towards the surface by the $\mathrm{O}-\mathrm{Ag}$ bonds. The amplitude of the surface buckling is largest for $\mathrm{Ag}(110)$, being $0.22 \AA$, compared to that for $\operatorname{Ag}(100)$ and $\mathrm{Ag}(111), 0.19 \AA$ and $0.17 \AA$, respectively. In the sequence $\operatorname{Ag}(111), \operatorname{Ag}(100), \operatorname{Ag}(110)$, the coordination number of the surface atoms decreases as $9>8>6$. Thus, the surface atoms are less tightly bound to the bulk in this series, which is reflected by their displacements due to the interaction with the PTCDA. Yet, for the (110) surface, the repulsion of the Ag atoms directly below the perylene core is smaller compared to (100) and (111). This indicates additional attractive interactions for these atoms, as will be discussed below. From the adsorption geometries, we calculated the average bond lengths $b$ between the $\mathrm{O}_{\text {carb }}$, the $\mathrm{O}_{\text {anhyd }}$, as well as the $\mathrm{C}_{\text {funct }}$ atoms and the neighboring $\mathrm{Ag}$ surface atoms. We considered two Ag neighbors in the case of (off-)bridge adsorption sites and one for (off-)on-top adsorption sites, respectively. As can be seen from Fig. 4(a) (dashed lines), $b\left(\mathrm{C}_{\text {funct }}-\mathrm{Ag}\right)$ does not alter much for the three $\mathrm{Ag}$ faces and is too long for a covalent interaction (minimal $3.08 \pm 0.07 \AA$ ). However, $b\left(\mathrm{O}_{\text {carb } / \text { anhyd }}-\mathrm{Ag}\right)$ shortens for both types of $\mathrm{O}$ atoms, the more open the substrate surface is. In particular, $b\left(\mathrm{O}_{\text {anhyd }}-\mathrm{Ag}\right)$ reduces from $3.37 \pm 0.04 \AA$ (=sum of the $\mathrm{vdW}$ radii $^{24}$ ) to $2.55 \pm 0.02 \AA$, i.e. by $25 \%$, from $\mathrm{Ag}(111)$ to $\mathrm{Ag}(110)$. Finally, it is close to $b\left(\mathrm{O}_{\text {carb }}-\mathrm{Ag}\right)$, being $2.37 \pm 0.04 \AA$ for PTCDA/Ag(110). The reduction of the difference in $b(\mathrm{O}-\mathrm{Ag})$ for $\mathrm{O}_{\text {carb }}$ and $\mathrm{O}_{\text {anhyd }}$ points to a stronger hybridization of the electronic states of the adsorbed PTCDA with metal states, as is also visualized by DFT below. This leads to a larger distortion of the $\mathrm{C}$ backbone and to a

TABLE III. Experimental and theoretical results for the adsorption geometry of PTCDA on the low-index Ag surfaces. Here, $d^{\text {exp/theo }}$ values denote the averaged vertical adsorption heights of the specific atoms obtained from NIXSW experiments and DFT calculations, respectively (all values in $\AA$, n.d. = not determined). For the specification of the atoms see Fig. 4(b).

\begin{tabular}{|c|c|c|c|c|c|c|}
\hline & \multicolumn{2}{|c|}{$\operatorname{Ag}(111)$} & \multicolumn{2}{|c|}{$\operatorname{Ag}(100)$} & \multicolumn{2}{|c|}{$\operatorname{Ag}(110)$} \\
\hline & $d^{\exp }$ (Ref. 15) & $d^{\text {theo }}$ & $d^{\exp }$ & $d^{\text {theo }}$ & $d^{\exp }$ & $d^{\text {theo }}$ \\
\hline $\mathrm{C}$ total & $2.86 \pm 0.01$ & 2.99 & $2.81 \pm 0.02$ & 2.78 & $2.56 \pm 0.01$ & 2.68 \\
\hline $\mathrm{C}_{\text {peryl }}$ & n.d. & 3.00 & $2.84 \pm 0.02$ & 2.80 & $2.58 \pm 0.01$ & 2.71 \\
\hline $\mathrm{C}_{\text {funct }}$ & n.d. & 2.94 & $2.73 \pm 0.01$ & 2.69 & $2.45 \pm 0.11$ & 2.53 \\
\hline O total & $2.86 \pm 0.02$ & 2.86 & $2.64 \pm 0.02$ & 2.59 & $2.33 \pm 0.03$ & 2.40 \\
\hline $\mathrm{O}_{\text {carb }}$ & $2.66 \pm 0.03$ & 2.80 & $2.53 \pm 0.02$ & 2.53 & $2.30 \pm 0.04$ & 2.38 \\
\hline $\mathrm{O}_{\text {anhyd }}$ & $2.98 \pm 0.08$ & 2.98 & $2.78 \pm 0.02$ & 2.71 & $2.38 \pm 0.03$ & 2.46 \\
\hline
\end{tabular}



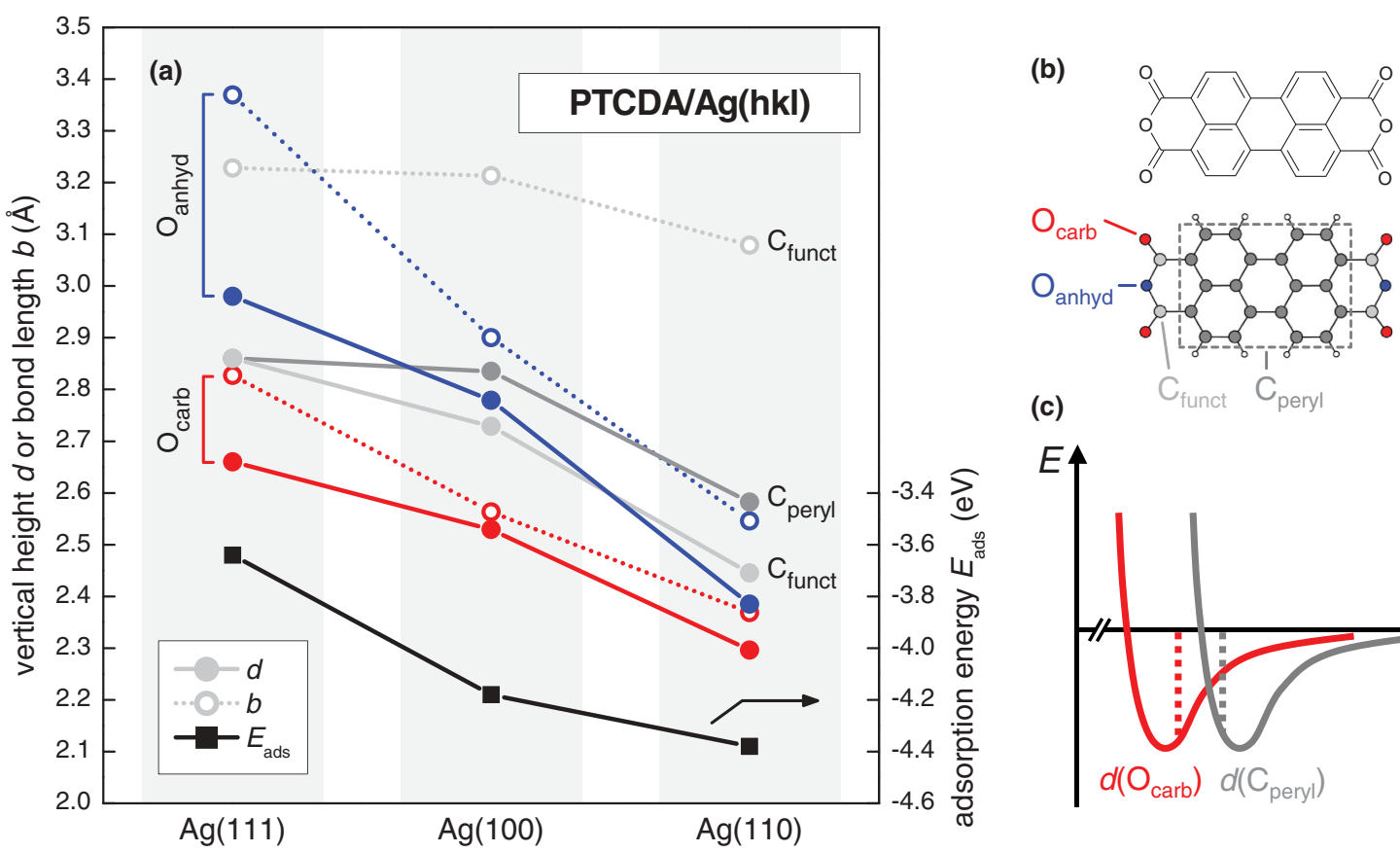

(c)

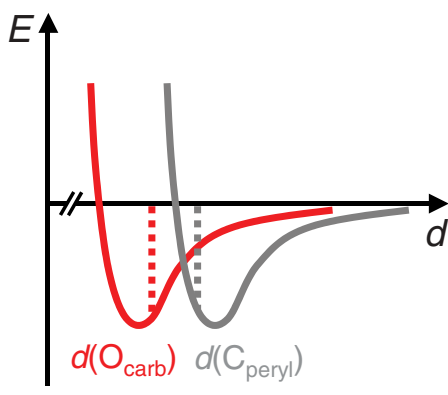

FIG. 4. (Color) (a) Averaged vertical heights $d$ (solid lines,, ) and bond lengths $b$ to neighboring surface atoms (dotted lines, $\mathbf{0}$ ) for PTCDA adsorption on the low index Ag surfaces. Gray: $\mathrm{C}_{\text {peryl }}$, light gray: $\mathrm{C}_{\text {funct }}$, red: $\mathrm{O}_{\text {carb }}$, blue: $\mathrm{O}_{\text {anhyd }}$. Error bars are omitted for clarity; lines are guides to the eye. The calculated adsorption energy $E_{\text {ads }}$ per molecule is also indicated (black solid line, $\mathbf{\square}$ ). (b) Valence bond structure (top) and ball-and-stick model (bottom) of PTCDA. (c) Schematic binding scenario for PTCDA on Ag surfaces: Contributions of $\mathrm{C}_{\text {peryl }}$ (gray) and $\mathrm{O}_{\text {carb }}$ (red) to the potential energy $E$ as a function of the adsorption height $d$. Realized values for $d$ in the molecule are marked by dashed lines.

subsequent loss of the mesomeric stabilization within the molecule. Apparently, the energetic cost of the deformation is counterbalanced by the energy gain through the formation of covalent $\mathrm{O}-\mathrm{Ag}$ bonds. This holds for all $\mathrm{O}$ atoms, although for $\mathrm{O}_{\text {anhyd }}$ the interaction is less pronounced as judged from the larger $b$.

In conclusion: For longer $\mathrm{O}-\mathrm{Ag}$ bonds, the $\mathrm{C}$ backbone of the adsorbed PTCDA is less distorted, and $d\left(\mathrm{C}_{\text {peryl }}\right)$ is larger. As a consequence of the generally small values of $b\left(\mathrm{O}_{\text {carb/anhyd }}{ }^{-}\right.$ $\mathrm{Ag})$, the substrate/perylene core interactions become locally repulsive. The corresponding binding potential for PTCDA can schematically be split into the contributions of these two bonding channels, which are sketched in Fig. 4(c): The minimum of the potential that is felt by $\mathrm{O}_{\text {carb }}$ is at a smaller distance $d$ from the surface than the minimum for $\mathrm{C}_{\text {peryl }}$. Hence, the overall adsorption height of the molecule can be understood as a compromise between attractive $\mathrm{O}-\mathrm{Ag}$ interactions and partly repulsive $\mathrm{C}_{\text {peryl }}-\mathrm{Ag}$ interactions. The above-noted buckling amplitude is larger and $b(\mathrm{O}-\mathrm{Ag})$ is shorter for lower surface atom coordination numbers. This correlation of coordination number and strength of local bonding was recently also emphasized in Ref. 53. We conclude that the strength of the $\mathrm{O}_{\text {carb }}-\mathrm{Ag}$ bonds, and to some extent also the $\mathrm{O}_{\text {anhyd }}-\mathrm{Ag}$ bonds, plays a prominent, possibly decisive role for the adsorption height and for the distortion of the PTCDA molecule.

\section{B. Electronic structure}

We now discuss the electronic structure. The formation of covalent O-Ag bonds is shown in Fig. 5 (top). The electron density $\rho(\mathbf{r})$ between the $\mathrm{O}_{\text {carb }}$ and the nearest Ag surface atoms increases from $\mathrm{Ag}(111)$ over $\mathrm{Ag}(100)$ to $\mathrm{Ag}(110)$. Here,
$\rho_{\mathrm{b}}\left(\mathrm{O}_{\mathrm{carb}}-\mathrm{Ag}\right)$ at the bond critical point (of the type $\left.3,-1\right)$ is found to be approximately $0.25 \mathrm{e}^{-} / \AA^{3}$ in the latter case, while for PTCDA on $\operatorname{Ag}(100)$ and $\operatorname{Ag}(111)$, smaller values are found ( 0.20 and $0.12 \mathrm{e}^{-} / \AA^{3}$, respectively). Additionally, electrons accumulate between the $\mathrm{O}_{\text {anhyd }}$ and the $\mathrm{Ag}$ atoms in the same series. This proves the above-noted evolution of $\mathrm{O}_{\text {carb/anhyd }}$ - Ag bonds with decreasing Ag coordination number. Their development can also be identified in the electron density difference $\Delta \rho(\mathbf{r})$ (Fig. 5, second row), which is defined as $\rho(\mathbf{r})$ of the bonded system PTCDA/Ag(hkl) minus $\rho(\mathbf{r})$ of the free (but distorted) PTCDA molecule and minus $\rho(\mathbf{r})$ of the bare (but buckled) Ag(hkl) surface. The electron density enhances around the $\mathrm{O}$ atoms, while it is reduced directly above the surface, indicating (polar) covalent O-Ag bonds. Presumably, these bonds are of coordinative nature. Again, this effect is most prominent for the most open (110) surface. Therefore, an important aspect of the bonding is the formation of the covalent $\mathrm{O}-\mathrm{Ag}$ bonds.

At first glance, the result that (only) local O-Ag interactions determine the PTCDA adsorption geometry is in apparent contradiction to our recent discussions of the bonding model of PTCDA within the Newns-Anderson model. ${ }^{15,54}$ Therein, the chemical interaction between the adsorbate and the substrate is based on the energetic lowering and hybridization of a molecular acceptor state with metal states and a charge transfer to the adsorbate, i.e. (partial) filling of the former acceptor state. ${ }^{6}$ For PTCDA on Ag surfaces, this charge transfer into the former lowest unoccupied molecular orbital (LUMO) has experimentally been proven and been interpreted as the dominating bonding channel. ${ }^{55}$ Hence, we calculated the metal-to-molecule charge transfer $\Delta q$ : From a Bader 
(a) $\mathrm{Ag}(111)$
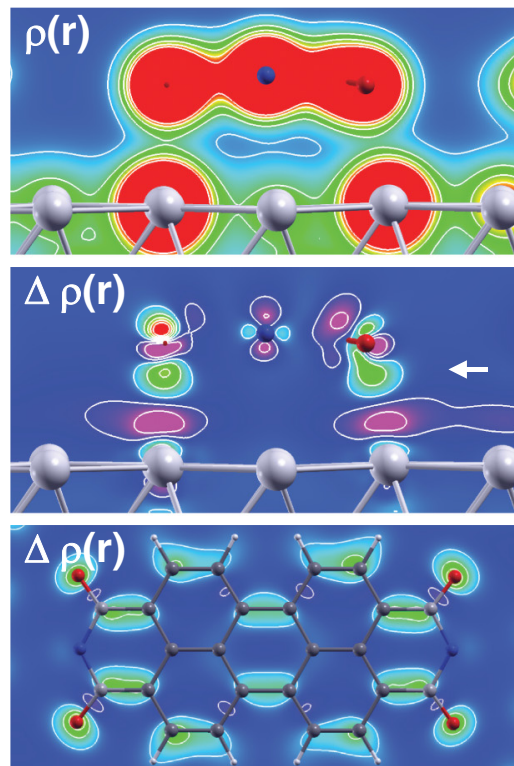

(d)

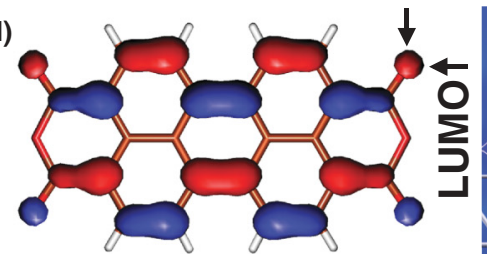

(b) $\mathrm{Ag}(100)$
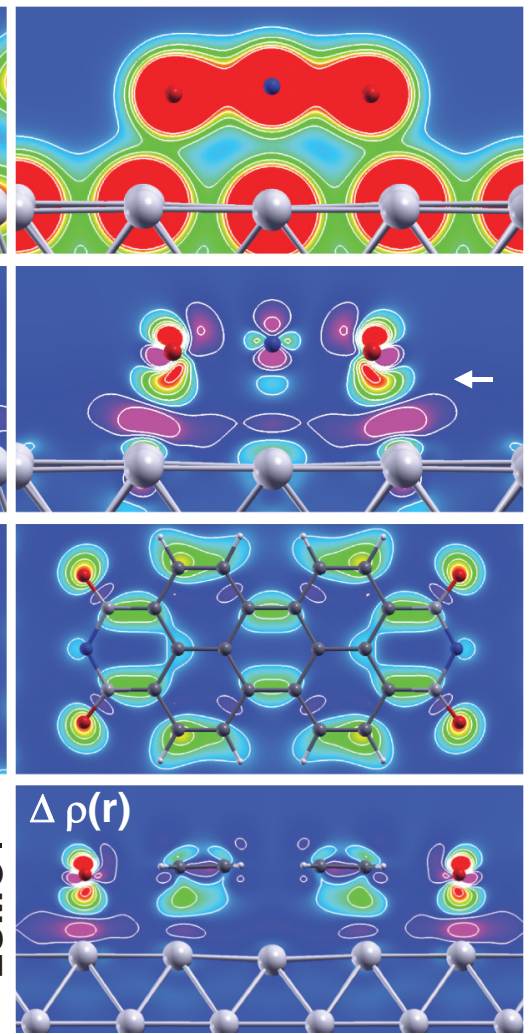

(c) $\mathrm{Ag}(110)$

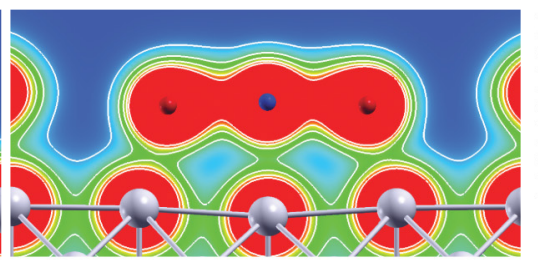

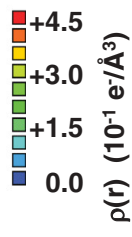

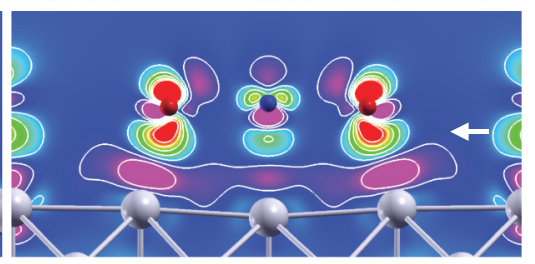

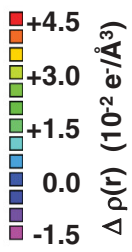
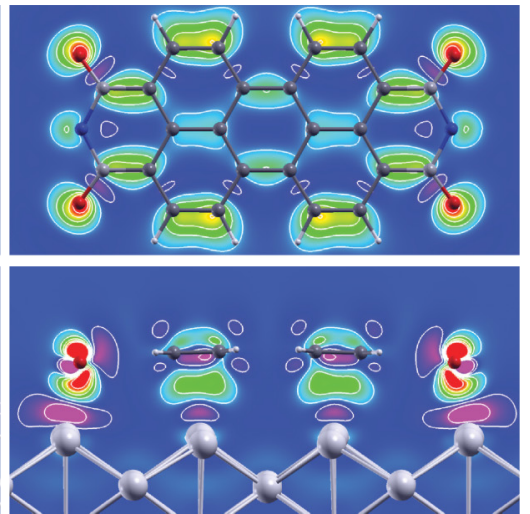

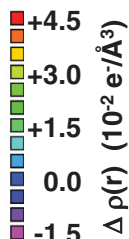

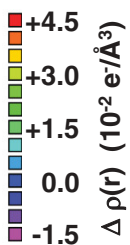

FIG. 5. (Color) Total electron density $\rho(\mathbf{r})$ and electron density difference $\Delta \rho(\mathbf{r})$ for PTCDA on (a) $\operatorname{Ag}(111)$, (b) $\operatorname{Ag}(100)$, and (c) $\operatorname{Ag}(110)$. First and second rows: side views along the long molecular axis; third row: top views; fourth row: side views along the short molecular axis. The horizontal cuts are made $0.8 \AA$ below the perylene core of the PTCDA molecule. Light gray: $\mathrm{Ag}$, white: $\mathrm{H}$, gray: $\mathrm{C}_{\text {peryl }}$, light gray: $\mathrm{C}_{\text {funct }}$, red: $\mathrm{O}_{\text {carb }}$, blue: $\mathrm{O}_{\text {anhyd }}$. (d) Lowest unoccupied molecular orbital (LUMO) of gas-phase PTCDA. ${ }^{21}$ The black and white arrows indicate the positions of the vertical and horizontal cuts. Note that in (a) the PTCDA molecule is rotated against the [1110] substrate direction by $2^{\circ}$.

analysis, ${ }^{45}$ we indeed find a net $\Delta q$ of $1.00 \mathrm{e}^{-}, 1.33 \mathrm{e}^{-}$, and $1.35 \mathrm{e}^{-}$for $\operatorname{Ag}(111), \operatorname{Ag}(100)$, and $\operatorname{Ag}(110)$, respectively. (We note that Bader analysis tends to overestimate the absolute charges. $\left.{ }^{56}\right)$ This can also be seen in the plots of $\Delta \rho(\mathbf{r})$ in Fig. 5 (third row). The charge that is donated from the metal to the PTCDA accumulates in a metal/molecule hybrid state, ${ }^{57}$ which very much resembles the LUMO of the free molecule [see Fig. 5(d)]. Several aspects of the interface bonding can be rationalized here: (a) The metal-to-molecule charge transfer leads to a (partial) filling of the former LUMO state. Thereby, the electron density on the molecule changes towards that of a quinoidal structure. ${ }^{4,20}$ (b) This leads to the weakening of the $\mathrm{C}_{\text {funct }}=\mathrm{O}_{\text {carb }}$ double bonds (to which the former LUMO is antibonding) and causes charge depletion between these atoms (see Fig. 5, third row). (c) Thus, the charge transfer supports the formation of covalent $\mathrm{O}-\mathrm{Ag}$ bonds by enhancing the flexibility of the PTCDA molecule. The features (a)-(c) systematically increase in the sequence $\operatorname{Ag}(111), \operatorname{Ag}(100), \operatorname{Ag}(110)$, that is with lower surface atom coordination number. Thus, beside the covalent bonding of the $\mathrm{O}_{\text {carb }}$ atoms (and partially of the $\mathrm{O}_{\text {anhyd }}$ atoms) to the surface, charge donation from the surface into the former LUMO is also an important aspect.

We emphasize that the charge donation is still of bonding character for all Ag surfaces, despite the repulsion of surface atoms by the perylene core. Figure 3 (third and fourth row) shows the accumulation of charge also between the $\mathrm{C}_{\text {peryl }}$ atoms on the periphery of the PTCDA molecule and the Ag surface atoms, and thus the formation of (weak) covalent/coordinative bonds. The repulsion of the $\mathrm{Ag}$ atoms is only observed where the electron density of the metal/molecule hybrid state is marginal, i.e. underneath the long central axis of the PTCDA molecule (see Fig. 1), which coincides with the nodal plane of the LUMO. In the case of PTCDA/Ag(110), however, a strong hybridization of the molecular states with metal states causes an accumulation of electron density also below the long central axis of the adsorbed molecule, indicating additional attractive interactions with the surface. This explains the above-mentioned smaller repulsion of the Ag atoms there. Hence, the interaction between the substrate and the central $\pi$ system has to be seen as a combination of charge transfer, attractive $\pi$ interactions (to a small extent delocalized), and local Pauli repulsion.

\section{SUMMARY}

In summary, for PTCDA on Ag surfaces, the bonding channels are as follows: (a) Local covalent bonds evolve between the $\mathrm{O}$, especially the $\mathrm{O}_{\text {carb }}$, and the Ag surface atoms 
(bonding). (b) There is a metal-to-adsorbate charge transfer over the entire molecule. (c) The interaction turns (partially) repulsive on the perylene core, but (d) in cases of strong $\mathrm{O}-\mathrm{Ag}$ bonding, i.e. for the open surfaces, attractive $\mathrm{C}_{\text {peryl }}-\mathrm{Ag}$ interactions on some of the perylene core atoms evolve. The formation of the local O-Ag bonds is supported by the charge donation, which results in a (partial) rehybridization of the molecular orbitals. This, in turn, allows the PTCDA $\mathrm{O}$ atoms and, subsequently, the perylene core to move closer to the surface, further facilitating the charge transfer. The bonding mechanism of PTCDA to Ag surfaces, hence, proceeds in a complex and synergistic interaction cycle, bearing similarities to the Blyholder model. ${ }^{5}$ For the more open surfaces, the covalent $\mathrm{O}-\mathrm{Ag}$ bonds are significantly shorter as a consequence of a reinforced interaction cycle. We suggest that this picture also holds for other $\pi$-conjugated planar molecules on surfaces.

\section{ACKNOWLEDGMENTS}

We thank J. Zegenhagen, B. Detlefs, Y. Mi, and J. Duvernay (ESRF) for helpful discussions and experimental support. Financial support by the ESRF and the DFG under the projects SFB 624, SFB 813, SO 407/6-1, and Ta244/3-1/2 are acknowledged.
*Corresponding author: bauer@pc.uni-bonn.de

${ }^{1}$ A. Hauschild, K. Karki, B. C. C. Cowie, M. Rohlfing, F. S. Tautz, and M. Sokolowski, Phys. Rev. Lett. 94, 036106 (2005).

${ }^{2}$ W. Ji, Z. Y. Lu, and H. J. Gao, Phys. Rev. B 77, 113406 (2008).

${ }^{3}$ L. Kilian, A. Hauschild, R. Temirov, S. Soubatch, A. Schöll,

A. Bendounan, F. Reinert, T. L. Lee, F. S. Tautz, M. Sokolowski, and E. Umbach, Phys. Rev. Lett. 100, 136103 (2008).

${ }^{4}$ L. Romaner, D. Nabok, P. Puschnig, E. Zojer, and C. AmbroschDraxl, New J. Phys. 11, 053010 (2009).

${ }^{5}$ G. Blyholder, J. Phys. Chem. 68, 2772 (1964).

${ }^{6}$ D. M. Newns, Phys. Rev. 178, 1123 (1969).

${ }^{7}$ R. Hoffmann, Angew. Chem., Int. Ed. 26, 846 (1987).

${ }^{8}$ B. Hammer, Y. Morikawa, and J. K. Nørskov, Phys. Rev. Lett. 76, 2141 (1996).

${ }^{9}$ J. K. Nørskov, Rep. Prog. Phys. 53, 1253 (1990).

${ }^{10}$ P. S. Bagus and F. Illas, J. Chem. Phys. 96, 8962 (1992).

${ }^{11}$ M. Eremtchenko, J. A. Schaefer, and F. S. Tautz, Nature 425, 602 (2003).

${ }^{12}$ K. Glöckler, C. Seidel, A. Soukopp, M. Sokolowski, E. Umbach, M. Böhringer, R. Berndt, and W. D. Schneider, Surf. Sci. 405, 1 (1998).

${ }^{13}$ J. Ikonomov, O. Bauer, and M. Sokolowski, Surf. Sci. 602, 2061 (2008).

${ }^{14}$ D. P. Woodruff, Prog. Surf. Sci. 57, 1 (1998).

${ }^{15}$ A. Hauschild, R. Temirov, S. Soubatch, O. Bauer, A. Schöll, B. C. C. Cowie, T. L. Lee, F. S. Tautz, and M. Sokolowski, Phys. Rev. B 81, 125432 (2010).

${ }^{16}$ G. Kresse and D. Joubert, Phys. Rev. B 59, 1758 (1999).

${ }^{17}$ G. Kresse and J. Furthmüller, Phys. Rev. B 54, 11169 (1996).

${ }^{18}$ J. P. Perdew, K. Burke, and M. Ernzerhof, Phys. Rev. Lett. 77, 3865 (1996).

${ }^{19}$ S. Grimme, S. Ehrlich, and L. Goerigk, J. Comput. Chem. 32, 1456 (2011).

${ }^{20}$ M. Rohlfing, R. Temirov, and F. S. Tautz, Phys. Rev. B 76, 115421 (2007).

${ }^{21}$ O. Bauer, G. Mercurio, M. Willenbockel, W. Reckien, C. H. Schmitz, B. Fiedler, S. Soubatch, T. Bredow, F. S. Tautz, and M. Sokolowski (unpublished).

${ }^{22}$ G. Mercurio, O. Bauer, M. Willenbockel, W. Reckien, C. H. Schmitz, B. Fiedler, S. Soubatch, T. Bredow, M. Sokolowski, and F. S. Tautz (unpublished).

${ }^{23}$ L.-G. Liu and W. A. Bassett, J. Appl. Phys. 44, 1475 (1973).

${ }^{24}$ S. K. M. Henze, O. Bauer, T. L. Lee, M. Sokolowski, and F. S. Tautz, Surf. Sci. 601, 1566 (2007).
${ }^{25}$ CasaXPS: Processing Software for XPS, AES, SIMS and More, version 2.3.16, Casa Software Ltd, Teignmouth, Devon, United Kingdom (2010).

${ }^{26}$ A. C. Thompson, D. T. Attwood, E. M. Gullikson, M. R. Howells, J. B. Kortright, A. L. Robinson, J. H. Underwood, K. J. Kim, J. Kirz, I. Lindau, P. Pianetta, H. Winick, G. P. Williams, and J. H. Scofield, X-Ray Data Booklet, 2nd ed. (Lawrence Berkeley National Laboratory, Berkeley, CA, 2001).

${ }^{27}$ J. F. Moulder, W. F. Stickle, P. E. Sobol, and K. Bomben, Handbook of X-ray Photoelectron Spectroscopy, 2nd ed. (PerkinElmer Corporation, Physical Electronics Division, Eden Prairie, MN, 1992).

${ }^{28}$ D. A. Shirley, Phys. Rev. B 5, 4709 (1972).

${ }^{29} \mathrm{G}$. Mercurio, Study of Molecule-Metal Interfaces by Means of the Normal Incidence X-ray Standing Wave Technique, Schriften des Forschungszentrums Jülich, Reihe Schlüsseltechnologien Vol. 49 (Dissertation, RWTH Aachen University, 2012), available at http://www.fz-juelich.de/zb/juwel.

${ }^{30}$ O. Bauer, and M. Sokolowski, XSWAVES - An XSW Data Evaluation Routine for ORIGIN 8, version 2.31 (2010), available from: http://www.thch.unibonn.de/pctc/sokolowski/ XSWAVES/XSWAVES_index.html.

${ }^{31}$ Torricelli is an XSW data analysis and simulation program written by G. Mercurio, copies can be obtained from s.tautz@fz-juelich.de.

${ }^{32}$ J. J. Lee, C. J. Fisher, D. P. Woodruff, M. G. Roper, R. G. Jones, and B. C. C. Cowie, Surf. Sci. 494, 166 (2001).

${ }^{33}$ I. Vartanyants, T. L. Lee, S. Thiess, and J. Zegenhagen, Nucl. Instrum. Methods Phys. Res., Sect. A 547, 196 (2005).

${ }^{34}$ D. P. Woodruff, Rep. Prog. Phys. 68, 743 (2005).

${ }^{35}$ A. Jablonski, F. Salvat, and C. J. Powell, NIST Standard Reference Database 64, version 3.1 (2003).

${ }^{36}$ M. B. Trzhaskovskaya, V. I. Nefedov, and V. G. Yarzhemsky, At. Data Nucl. Data Tables 77, 97 (2001).

${ }^{37}$ J. Stanzel, W. Weigand, L. Kilian, H. L. Meyerheim, C. Kumpf, and E. Umbach, Surf. Sci. 571, L311 (2004).

${ }^{38}$ G. Kresse and J. Hafner, Phys. Rev. B 47, 558 (1993).

${ }^{39}$ G. Kresse and J. Hafner, Phys. Rev. B 49, 14251 (1994).

${ }^{40}$ S. Grimme, J. Comput. Chem. 27, 1787 (2006).

${ }^{41}$ S. Grimme, J. Antony, S. Ehrlich, and H. Krieg, J. Chem. Phys. 132, 154104 (2010).

${ }^{42}$ W. Reckien and T. Bredow, Chem. Phys. Lett. 508, 54 (2011).

${ }^{43}$ W. Reckien, B. Kirchner, F. Janetzko, and T. Bredow, J. Phys. Chem. C 113, 10541 (2009). 
${ }^{44}$ R. F. W. Bader, Atoms in Molecules: A Quantum Theory (Oxford University Press, New York, 1990).

${ }^{45}$ G. Henkelman, A. Arnaldsson, and H. Jónsson, Comput. Mater. Sci. 36, 354 (2006).

${ }^{46}$ A. Kokalj, Comput. Mater. Sci. 28, 155 (2003).

${ }^{47}$ A. Gerlach, S. Sellner, F. Schreiber, N. Koch, and J. Zegenhagen, Phys. Rev. B 75, 045401 (2007)

${ }^{48}$ C. Stadler, S. Hansen, A. Schöll, T. L. Lee, J. Zegenhagen, C. Kumpf, and E. Umbach, New J. Phys. 9, 50 (2007).

${ }^{49}$ J. Zegenhagen, Surf. Sci. Rep. 18, 202 (1993).

${ }^{50}$ For PTCDA/Ag(111), the distortion of the C backbone has experimentally not been determined (see Refs. 1 and 15). Due to the saddle-like adsorption conformation of the molecule, we assume that the $\mathrm{C}_{\text {funct }}$ atoms reside at an adsorption height close to $d(\mathrm{O}$ average). The $\mathrm{C}$ backbone distortion is thus expected to be marginal.

${ }^{51}$ M. Böhringer, W. D. Schneider, K. Glöckler, E. Umbach, and R. Berndt, Surf. Sci. 419, L95 (1998).
${ }^{52}$ A. Kraft, R. Temirov, S. K. M. Henze, S. Soubatch, M. Rohlfing, and F. S. Tautz, Phys. Rev. B 74, 041402(R) (2006).

${ }^{53}$ D. Kreikemeyer-Lorenzo, W. Unterberger, D. A. Duncan, M. K. Bradley, T. J. Lerotholi, J. Robinson, and D. P. Woodruff, Phys. Rev. Lett. 107, 046102 (2011).

${ }^{54}$ F. S. Tautz, Prog. Surf. Sci. 82, 479 (2007).

${ }^{55}$ Y. Zou, L. Kilian, A. Schöll, T. Schmidt, R. Fink, and E. Umbach, Surf. Sci. 600, 1240 (2006)

${ }^{56}$ F. De Proft, C. Van Alsenoy, A. Peeters, W. Langenaeker, and P. Geerlings, J. Comput. Chem. 23, 1198 (2002).

${ }^{57}$ The projected density of states (PDOS, not shown) verifies that, independent of the substrate face, $\operatorname{Ag} s, p$, as well as $d$ states contribute to the metal/molecule hybrid state.

${ }^{58}$ For reasons of clarity, the depicted PTCDA molecule has exactly been aligned with the substrate direction; although, in our calculations as well as in previous investigations (see Ref. 25), it is found at a small angle $\left(2^{\circ}\right)$ with respect to the substrate lattice. As a consequence, the vertical positions of the respective surface atoms have been averaged. 